\title{
Mental Health in Former Soviet Countries: From Past Legacies to Modern Practices
}

\author{
Ionela Petrea, $\mathrm{PhD}, \mathrm{MSc}^{1}$
}

\begin{abstract}
Introduction: For decades, the image of mental health in Soviet countries has been associated with past political abuses in psychiatry, stigmatising attitudes and discriminating practices against people with any form of disability. Twenty years after the fall of the Soviet Union, the tainted reputation of psychiatry still persists. Living conditions in mental hospitals remain poor, sometimes inhumane and treatment of people with mental health problems is still marked by paternalistic, disempowering, even abusive practices. The Soviet practice of hiding people deemed disabled translates nowadays into the practice of relocating people with the most severe mental illnesses from mental health hospitals to social care institutions, outside the jurisdiction of the health sector, and outside the scope of mental health reforms.

Size of the problem. Morbidity rates from mental health problems in former Soviet countries are similar to those in other European countries. But suicides rates are the highest in Europe, particularly among men, despite decreases since 2000.

Resources and organisation. Mental health expenditures account for only three percent of health budgets, in these countries, mostly spent on large psychiatric hospitals. Former Soviet countries have similar organisations of services, but the Russian Federation, Belarus and Kazakhstan report significantly higher resources (services and staff) than the other CIS countries. A contributing factor is the migration of staff from lower income economies, facilitated by similarities between the education and health systems, and fluency in the Russian language.

Reforms of specialist services. Besides the development of policy and legislation, progress in implementing reform priorities can be traced mainly to projects that benefited from expert and financial support from international partners. Namely: setting up pilot mental health centres, advocacy for human rights of patients and building capacity in primary care.

Mental health in primary care. Introducing mental health services in primary care is challenging due to limitations in roles of primary care staff, but also in their competencies and skills, and their reluctance to take on more responsibilities.
\end{abstract}

\footnotetext{
${ }^{1}$ Head, Department of International Mental Health, Trimbos Institute, Netherlands.

Corresponding Author Contact Information: Ionela Petrea at ipetrea@tribos.nl; Dept. International Mental Health, Trimbos Institute, Netherlands.
} 
Conclusions. With reforms in the early stages of implementation, and slim prospects of suitable resources for necessary developments, modern mental health services remain largely out of reach for most people in former Soviet countries in the near future.

Key Words: Post Soviet psychiatry, Commonwealth of Independent States, mental health services in former Soviet Union, health care reform, primary health care

Recommended Citation: Petrea, I. Mental health in former Soviet countries: from past legacies to modern practices. Public Health Reviews. 2013;34: epub ahead of print.

\section{INTRODUCTION}

\section{Legacies of the Soviet past*}

For decades, the image of mental health in Soviet countries has been associated with political abuses in psychiatry and stigmatising attitudes and discriminating practices against people with any form of disability or, what in the Soviet society was viewed as a "defect" and burden. ${ }^{1-6}$

Abusive admissions, diagnosis and treatment based on political grounds in psychiatric institutions in the Soviet Union are well documented. While reviewing the body of evidence on the history of abuse is outside the scope of this paper, it is important to examine some of the lasting effects of previous policies and practices, that continue to affect the former Soviet countries. ${ }^{* *}$ As such, many institutions that employed abusive practices in the past find it hard to shake off their tainted reputations. Efforts to distance themselves from the past are made harder while living conditions in many psychiatric hospitals remain poor and sometimes inhumane and treatment of people with mental health problems is still marked by paternalistic, disempowering, and even abusive practices (while no-longer politically motivated). Psychiatry as a profession is still in need of redeeming itself. International standing of psychiatrists in post-Soviet countries has improved since the times when Soviet psychiatrists were widely condemned for political abuses and led to leave the World Psychiatric Association ${ }^{7}$

\footnotetext{
* This article does not address the broader historical context of the Soviet period.

** For the purposes of this paper, the group of countries referred to as "former Soviet countries" includes Azerbaijan, Armenia, Belarus, Georgia, Kazakhstan, Kyrgyzstan, Republic of Moldova, Russian Federation, Tajikistan, Turkmenistan, Uzbekistan and Ukraine. The Baltic States are not covered, since their post Soviet development was substantially different from the other former Soviet countries, similar with other new EU Member States.
} 
Currently, the psychiatric associations of all but two former Soviet countries (Tajikistan and Turkmenistan) are members of the World Psychiatric Association. ${ }^{1}$ However, they have not yet regained the credibility and trust of the general population nor people with mental health problems. ${ }^{8,9}$

Another legacy of the Soviet past is the stigma and discrimination associated with mental illness. The notorious statement of a Soviet official at the Moscow Olympics in 1980 "There are no invalids in the USSR!" summarises the philosophy regarding people with any form of disability during Soviet times. ${ }^{10-12}$ More than 20 years on, the prevailing attitudes in the Soviet Union of "survival of the fittest" and abandonment of the weaker have endured, and continue to have harsh implications for people with mental health problems.

At a time when mental health services are undergoing reforms in many Central and Eastern European countries, and respect for human rights and dignity of patients is increasingly important, alongside with development of community-based services, people with the most severe mental illnesses continue to be ostracised and discriminated against in former Soviet countries. Mental hospitals are under pressure to decrease the number of beds and the duration of stay of people admitted. In absence of alternatives in the community, in some countries, professionals encourage families to admit people with severe and enduring mental health problems to internats (social asylums outside the jurisdiction of the health sector). ${ }^{13,14}$ Eventually, they even facilitate the paper work.

In other cases, when mental hospitals are closed, for various reasons (e.g., buildings reclaimed by owners from before nationalisation), this same group of patients are moved to internats, while people with less challenging health problems are referred to other mental hospitals. While health authorities, often working together with international donors barely get their heads around reforming the mental health services under the authorities of the ministries of health, a large proportion of people with severe mental illness are ignored. This situation is well known to all key stakeholders, but little or nothing is being done to address the plight of these patients. As such, the old Soviet practice of hiding people deemed disabled translates nowadays into the practice of relocating them from mental health hospitals to internats under the responsibility of ministries for social welfare and national authorities for people with disabilities. At the moment, mental health reforms do not extend to them, and they continue to receive care not too different from that in the Soviet era. 


\section{SIZE OF THE PROBLEM}

\section{The state of mental health among people in the former Soviet Union}

Data on mental health status among people from the Commonwealth of Independent States (CIS)*, Georgia, Turkmenistan and Ukraine is scarce. Unlike many other European countries, they do not have a tradition of carrying out surveys on the mental health of the population, using internationally standardised data collection methods, or a common set of indicators based on agreed definitions and diagnostic instruments. Of the post-Soviet countries, only Ukraine is part of the World Mental Health Survey. ${ }^{15}$ As such, the most frequently used source of data is the World Health Organization Global Burden of Disease project, which for these countries relies heavily on extrapolations from findings in a limited number of countries where epidemiological studies are carried out. ${ }^{16}$ This article will focus on mental health problems in a narrower sense, and will not address mental health problems of specific age groups (children or older people) or substance misuse problems.

The most recent available data shows that neuropsychiatric disorders are the second or the third largest cause of Disability-Adjusted Life Years (DALYs) among men in former Soviet Union countries, ranging from 11.1 percent in Turkmenistan, to 20.1 percent in Moldova. Among women, they are the first or second cause of DALYs, ranging from 16.4 percent in the Russian Federation to 21.9 percent in Uzbekistan (Table 1). These rates are only slightly lower than the European** average. ${ }^{17}$

While a far from perfect measure, one source of information that is available in all former Soviet countries is the suicide rate. The most recent available data shows that suicides are a major problem in all of the former Soviet countries. They have the highest suicide rates in the European Region: 18 per 100,000 population, as compared to the overall European Region rate of 13 per 100,000 population, and 10 per 100,000 population in the European Union. ${ }^{18}$ Among the former USSR countries, Belarus and Kazakhstan have the highest suicide rates both among men (47 and 41 respectively per 100,000 population) and women ( 8 per 100,000 population). Armenia and Georgia have suicide rates below those in the European Union

\footnotetext{
* The Commonwealth of Independent States (CIS) is a partnership on the basis of sovereign equality between 12 of the former Soviet Union republics (Azerbaijan, Armenia, Belarus, Kazakhstan, Kyrgyzstan, Republic of Moldova, Russian Federation, Tajikistan, Turkmenistan, Uzbekistan and Ukraine) formed in December 1991 (Available from URL: http://www.cisstat. com/eng/cis.htm).

${ }^{* *}$ Europe as defined in the United Nations system, with 53 Member States.
} 
countries. The most affected age groups, among both men and women, are those over 75 years old ( 71 and 17 per 100,000 respectively) and those aged between 45 and 59 (46 and 7 per 100,000 respectively).

Table 1

Disability-adjusted years of life for neuropsychiatric disorders in the Commonwealth of Independent States, Georgia, Turkmenistan and Ukraine

\begin{tabular}{l|c|c|c|c|c}
\hline \multicolumn{2}{l}{} & \multicolumn{2}{c}{ Male } & \multicolumn{2}{c}{ Female } \\
\hline Countries & Total & $\begin{array}{l}\text { Proportion of all } \\
\text { causes of DALYs }\end{array}$ & Ranking* & $\begin{array}{c}\text { Proportion of all } \\
\text { causes of DALYs }\end{array}$ & Ranking* \\
\hline Armenia & 17.6 & 14.7 & 2 & 20.7 & 1 \\
\hline Azerbaijan & 16.8 & 14.4 & 2 & 19.4 & 1 \\
\hline Belarus & 14.7 & 12.4 & 3 & 17.8 & 2 \\
\hline Georgia & 19.3 & 17.6 & 2 & 21.2 & 2 \\
\hline Kazakhstan & 14.6 & 13.0 & 3 & 16.7 & 2 \\
\hline Kyrgyzstan & 14.4 & 12.1 & 3 & 17.3 & 2 \\
\hline Republic of Moldova & 19.6 & 20.1 & 1 & 19.0 & 2 \\
\hline Russian Federation & 13.7 & 12.0 & 3 & 16.4 & 2 \\
\hline Ukraine & 13.6 & 11.4 & 3 & 16.5 & 2 \\
\hline Uzbekistan & 19.1 & 16.5 & 2 & 21.9 & 1 \\
\hline Tajikistan & 14.8 & 13.2 & 3 & 16.7 & 1 \\
\hline Turkmenistan & 13.9 & 11.1 & 4 & 17.5 & 2 \\
\hline
\end{tabular}

${ }^{*}$ This column indicates how neuropsychiatric disorders rank in each country, as compared to other disorders.

Source: Based on data from: World Health Organization. The global burden of disease: 2004 update. Geneva: World Health Organization; 2008. ${ }^{16}$

Over the last ten years, suicide rates among men have decreased in most former Soviet countries, after a sharp increase from the early 1980s to 2000 (Figure 1). Like in the other European countries, suicide rates among women in most former Soviet countries have been on a steady decrease since the 1980s, with slight increases noted only in Moldova and Georgia (Figure 2). Despite the decreases in male suicides since 2000, according to the most recent available data, men in former Soviet countries remain particularly vulnerable. Over six times more men than women are lost to suicide annually in these countries ( 32 versus 6 per 100,000 population). Differences between men in former Soviet countries and men in other 
European countries are also striking. For example, Belarusian men are twice as likely to commit suicide than an average European (47 versus 22 per 100,000 population).

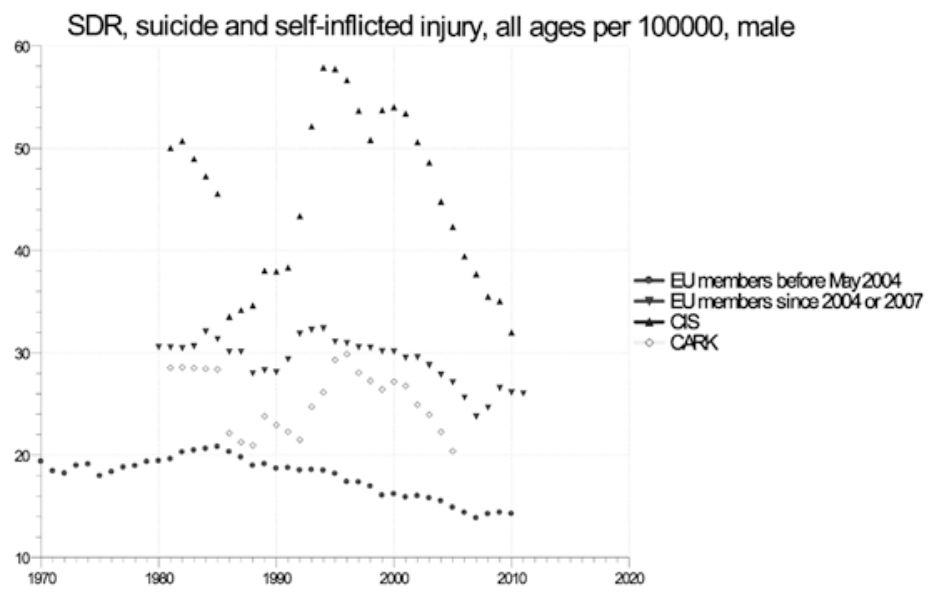

Fig. 1. Trends in suicide rates among men in the Commonwealth of Independent States, Georgia, Turkmenistan and Ukraine.

Source: WHO Regional Office for Europe. European Health for All Database. January 2013 (Accessed 11 April 2013). ${ }^{41}$

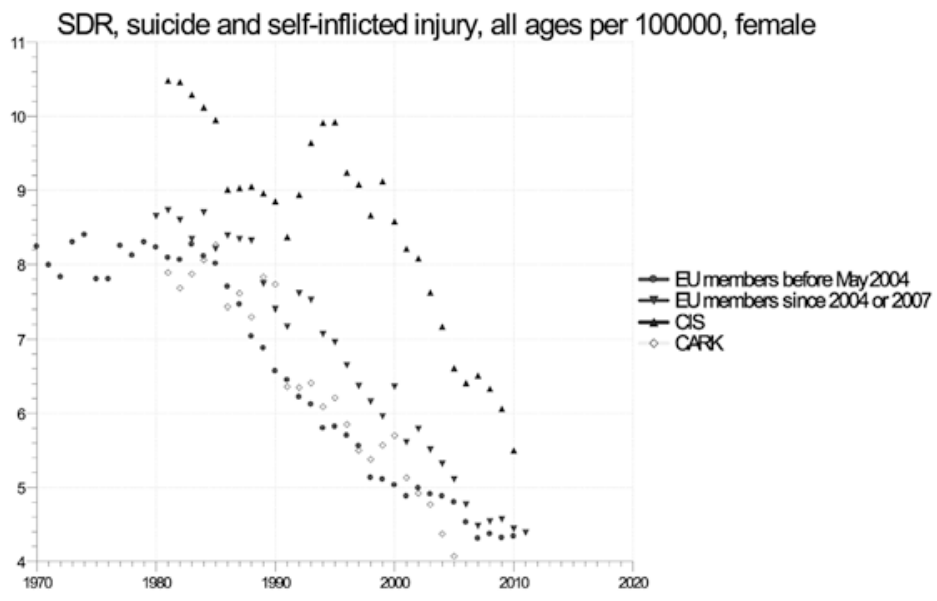

Fig. 2. Trends in suicide rates among women in the Commonwealth of Independent States, Georgia, Turkmenistan and Ukraine.

Source: WHO Regional Office for Europe. European Health for All Database. January 2013 (Accessed 11 April 2013). ${ }^{41}$ 
Despite the many methodological difficulties related to data on the mental health status of the population, and the resultant limitations of available data, what evidence exists indicates that mental health problems should be a leading health concern in the former Soviet countries.

Finally, though this article does not intend to cover substance abuse issues, it should be noted that many of these countries have a fast growing drug trafficking and substance abuse problem and responsibility for services provided to people with substance misuse problems lays with mental health professionals, while substitution therapy such as with methadone is officially frowned upon. ${ }^{19}$ In many of the former Soviet countries treatment and care for these problems are scarce and sometimes not existent (e.g., in Armenia, Russian Federation or Tajikistan, where there is no open access to services). Even where some services are available, they are often of poor quality, with key evidence based interventions not available to those in need. IV drug users are the main body sustaining the HIV/AIDS epidemic although the disease is also spreading in the general population.

\section{RESOURCES AND ORGANISATION OF MENTAL HEALTH SERVICES}

Considering the severity of the situation, it is important to understand whether appropriate treatment and care are available to those in need. For this purpose, this section presents a comparative analysis of the data on input and structures of the mental health systems in CIS countries, based on the data collected for the 2011 WHO Mental Health Atlas. ${ }^{20-29}$

Despite the high burden of disease, the level of investments in mental health remains low in all the CIS countries, at about three percent of their overall health budgets (lower than the European median of 5\%) Most of the care continues to be provided in large psychiatric hospitals that are the main beneficiaries of the mental health budget, receiving between 71 percent of funds in Georgia to 88 percent in Armenia. These rates are significantly higher than in other European countries (the European median is $60 \%$ ). As such, most of the care continues to be based in large psychiatric hospitals, with only an insignificant number of beds available in general hospitals or community services (Figure 3 ).

On a positive note, according to data provided by countries, over 90 percent of patients in Belarus and Uzbekistan are discharged within a year from admission. In the Russian Federation and in Georgia, discharge rates are slightly lower (76\% and 57\% respectively). In contrast, duration of stay continues to be high in the Republic of Moldova, where 64 percent of 
patients are admitted for more than a year to inpatient facilities, most of them spending up to five years in inpatient facilities.

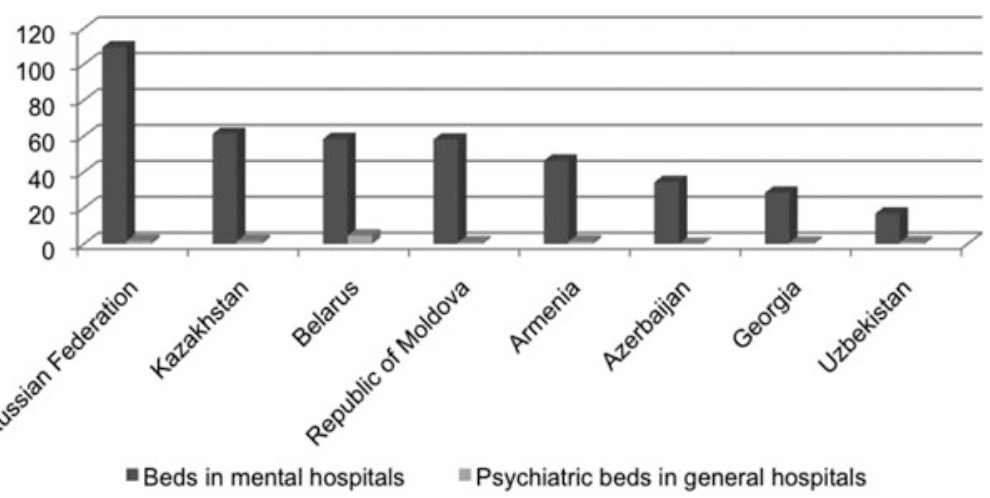

Fig. 3. Psychiatric beds in mental hospitals and in general hospitals, rate per 100,000 population.

Source: Based on data from the WHO Mental Health Atlas, 2011 (Accessed 20 January 2013). ${ }^{20-27,29}$

While organisation of services is similar across the CIS countries, the levels of resources they have available vary greatly, both in terms of services available to people with mental health problems and their access to health professionals.

The outpatient mental health facilities range from 3 per 100,000 in the Russian Federation and 1.5 per 100,000 in the Republic of Moldova to 0.1 per 100,000 in Azerbaijan and Uzbekistan. The European median is 1.47. Except for Russian Federation and Belarus, the rest of the countries have significantly lower rates of day treatment facilities than the European median of 0.3 per 100,000 population. Psychiatric beds are concentrated in mental hospitals.

Similar disparities are noticeable in inpatient services. Former Soviet countries have significantly fewer psychiatric beds in general hospitals than other European countries, despite higher total acute hospital bed ratios. The rates of psychiatric beds in general hospitals range from 4.7 in Belarus to 0.1 in Azerbaijan, while the European median is 10.5 per 100,000 population. Similarly, the number of beds in mental hospitals per 100,000 population range from as many as 109.5 in the Russian Federation, to around 60 in Kazakhstan, Belarus and the Republic of Moldova, and to 28 in Georgia and 17 in Uzbekistan. The European median is of 39.4. 
Human resources working in mental health services also vary greatly (Figure 4). The Russian Federation has around three times more psychiatrists per 100,000 population than Uzbekistan, Armenia or Azerbaijan, and more than six times more nurses per 100,000 population than Azerbaijan and Georgia. The Russian Federation and Belarus have more psychiatrists than the European median of 8.6, while the rest of the countries have significantly fewer. The Russian Federation has more than double the European median of nurses and psychologists. Belarus also has more of these professional groups than the European median. Psychologists are providing mental health services mainly in the Russian Federation and Belarus (5.4 and 3.4 respectively, per 100,000 population). In the other CIS countries, they are available in very low numbers, if at all. People with mental health problems in these countries rarely have access to social workers in the mental health services.

There is little data on the number of mental health professionals emigrating from different former Soviet countries. However, unofficial reports indicate that many professionals from countries with lower income economies emigrate to the Russian Federation. Their Russian language skills, an inheritance of the Soviet era, allow them to practice their speciality and the similarities between education and health systems ensure they can integrate easily into the new settings.

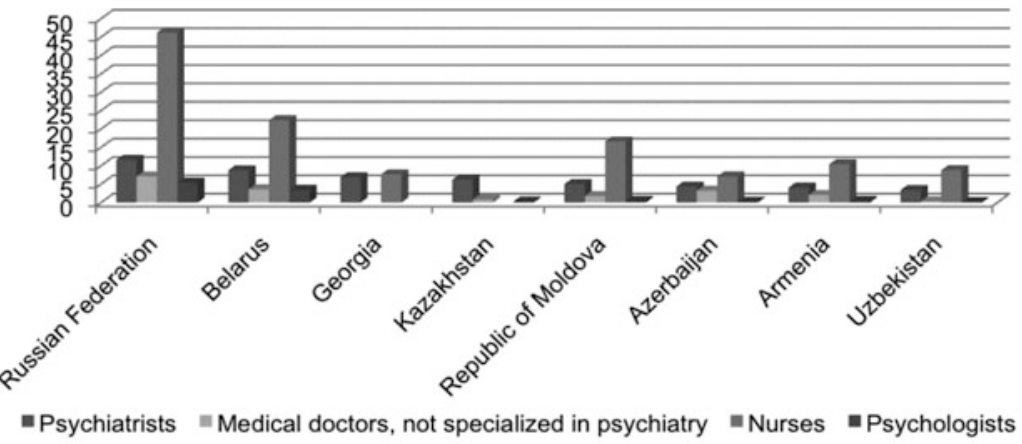

Fig. 4. Health professionals working in the mental health sector, rate per 100,000 population.

Source: Based on data from the WHO Mental Health Atlas, 2011. ${ }^{20-27,29}$

The data on the mental health services and staff available in the CIS countries provides an insight into the many challenges faced there by people with mental health problems. At the same time, they only tell half the story. To fully appreciate their implications and grasp the realities of 
mental health services users and of the decision makers with responsibilities for mental health, it is necessary to have a closer look at the dynamics from within the mental health systems. In particular, it is important to understand the impact of the Soviet past on current services and the challenges of reforming mental health services, both at the level of specialised services and in primary care.

\section{REFORM AGENDA FOR SPECIALIST MENTAL HEALTH SERVICES}

In Europe, it is largely accepted that a comprehensive range of mental health services in line with the evidence base and best practice internationally would consist of: a) modern inpatient care in different settings, and all older institutions having been closed; b) specialist and more general community based teams delivering domiciliary care, outreach to primary care, crisis services, assertive outreach and early intervention; c) 24-hour nursing care, residential care and supported housing for people with severe mental health problems who need it; and d) daytime activities and social support directed at rehabilitation and social inclusion. ${ }^{30}$ Such services are expected to deliver a range of health and social care interventions including medication, psychotherapy, social support and advice and nursing care.

CIS countries have a long road ahead before reaching such a complex model of modern mental health services, taking into account the current state of their mental health services, as described above. Setting up such new models of care requires substantial financial investments. ${ }^{8,31,32}$ There are no studies comparing cost-effectiveness of current care in CIS countries with that of introducing modern services. However, considering the low funding and poor conditions in current services, it is safe to assume the Western model of converting funds used in traditional services into funds for modern services will not work. When reforming their mental health systems, CIS countries will need to find solutions that are feasible within their cultural, financial and organisational context.

Considering the similarities in historical organisation of mental health services and the provision of mental health treatment and care, the reform agenda is similar across the CIS countries. In 2008, lead specialists from eight CIS countries signed the joint Merano Declaration on Mental Health in CIS Countries which identified shared challenges and areas of action for joint work. ${ }^{33}$ Some of the challenges are broad, requiring action at high governmental levels, such as defining effective mechanisms for implementing policy and legislation, or raising the low, inequitable level of funding allocated to mental health. At a service level, CIS mental health 
leaders focused on: improving the "poor conditions of mental health facilities with sometimes poor availability of food and medication, causing neglect and violation of human rights"; addressing the high demands on mental health specialists, unfeasible to cope with by the current workforce; and increasing ability of primary care to provide services to people with mental health problems.

Decision makers in health in CIS countries are faced with a difficult dilemma. On one side, they face pressures from the international community and donors to not make any more investments in large mental health hospitals, which ought to be either scaled down or completely closed. On the other side, if they want to improve their human rights record in mental health care, they would need to upgrade the buildings of these hospitals where most people with mental health problems live. The challenge is that prospects for developing community-based alternatives are not encouraging. Realistically, it will take years before such modern mental health services will be able to take over the care of people who are currently treated in large hospitals. What should governments do in the meantime? They can choose to not improve conditions in large hospitals, as they anyway can hardly afford to do it. But the outcome would be that people will continue to live in tough, even inhumane conditions for years, until enough community services become available, and social services (nowadays virtually nonexistent in most CIS countries) find housing for those who can in time return to independent living.

So far, besides the development of policy and legislation, progress in implementing reform priorities can be traced mainly for the priorities that benefited from expert and financial support from international partners, namely: setting up pilot mental health centres, advocacy on human rights of patients and developing curricula for primary care staff.

Pilot community mental health centres have been set up in some of the CIS countries, including Armenia, Moldova, the Russian Federation and Ukraine. ${ }^{34-36}$ Funded by international donors, such as the Swiss Agency for Development and Cooperation, the Geneva Initiative on Psychiatry, and the Stability Pact, they were expected to serve as examples of good practice and induce changes in the mental health systems. Donors expected that after the initial phase of international funding, the centres would be taken over by national or local authorities and integrated into the existing system. Moreover, there was an indirect expectation these model centres would be replicated in the system with national resources.

However, many of these expectations did not materialise. Experience since the collapse of the Soviet Union shows that mental health systems in 
most former Soviet countries are not able to replicate the pilot centres using their own resources. The funding required for setting up (renovating the space and employing multidisciplinary staff) is far above the possibilities of national systems. Asking social services and local authorities to provide housing in forms of shelters or protected homes, is largely unrealistic. While there are examples of such initiatives (e.g., in the Moldavian town Balti), ${ }^{37}$ scaling them up would require resources that are just not available. In many of the CIS countries with low income economies, mainstream, employed middle class people cannot afford housing and live in challenging conditions. In this context, it is hard to convince authorities to offer people with mental health problems what they cannot afford to give to any other population group, with or without disabilities or special needs. Instead, national stakeholders in CIS countries will need to find local solutions to deinstitutionalisation. Perhaps investing in building the capacity of social carers is a more realistic and cost-effective option. They could work with families and local communities on culturally sensitive and financially feasible options for family reintegration. With some external support, perhaps other local solutions can be identified.

Pilot community centres were successful when their set up was entrusted to local champions who were also experienced professionals. ${ }^{38}$ Due to their already established credibility with colleagues, as well as with local authorities, they managed to mobilise resources and turn their centres into actual examples of good practices. However, they required high levels of resources, not only for the initial investments, but also for daily operations. With complex multidisciplinary teams, they were able to provide a variety of services, from medication, to talking therapies, occupational therapies and social services. However, to accomplish all this, they can only work with a small number of patients. Considering the low level of resources in these countries, despite the qualitative advantages, this model of community services is not feasible to be scaled up in most of the CIS countries.

Besides financial challenges, certain organisational aspects hindered the scaling up of other pilot community centres. These centres were based in small non-governmental organisations and employed young staff with little or no experience in traditional services, in an effort to support local champions with fresh views. While this seemed like a sensible approach, in many places it was counter-productive, and resulted in the alienation of experienced professionals. The pilot centres, rather than becoming examples of good practices, were perceived as unfair competition by professionals working in traditional services. The noticeable difference in funding-both for upgrading facilities, and for salaries paid to staff-contributed to further animosities. ${ }^{32}$ Moreover, unlike staff in traditional services, staff 
in pilot centres benefited from training both in country and abroad. Thus, despite good intentions and enthusiasm, the young staff failed to gain professional credibility with their peers. One consequence was that in some locations, specialists from traditional inpatient and outpatient services refused to refer their patients to these new community centres, even after the centres were taken over by national funding. As a result, years after being set up, these pilot centres, with their beautiful buildings and multidisciplinary teams treat only a handful of patients.

\section{MENTAL HEALTH IN PRIMARY CARE}

\section{From theoretical agreement to practice}

Over the last two decades, primary care services have been reformed throughout the former Soviet countries and family medicine has been introduced as a new speciality. Under the Soviet model of care, people could access primary care services in policlinics (urban) or posts (rural), ${ }^{39}$ covering a small number of specialities, such as internists, pediatricians and gynecologists. ${ }^{40}$ People with mental health problems were referred directly to specialised services, called dispansers. A key goal of the reforms was to increase primary care responsibilities as gate-keepers for specialised services in all health areas, including mental health.

According to the most recent available data, in CIS countries there are 50 percent fewer family doctors then the European average. ${ }^{41}$ Only Turkmenistan has more family doctors than the European average (60.4 per 100,000 population). In countries like Kazakhstan, Tajikistan or Uzbekistan, there are only about 26 family doctors per 100,000 population.

As noted above, one of the priority areas for mental health reforms in CIS countries is to stream mental health care into primary care practice. There are many reasons behind the new demands on family doctors to take on responsibilities in mental health. To start with, this is expected to facilitate the shifting of services towards communities, alongside the development of community-based alternatives for specialist services. Introducing mental health in primary care can offer people with common mental health problems a low-threshold access to services that could identify, treat and diagnose these conditions. It is congruent with the antistigma and de-institutionalisation agenda-which are cornerstones in the modernisation of mental health systems. At the same time, tapping into the resources of primary care is seen as a means for dealing with the shortage of mental health specialists. 
Despite agreement among leading specialists, and international pressures to pursue this component of the mental health reforms, introducing mental health services in primary care faces a number of challenges. First, the roles of primary care staff in providing mental health services are limited. In Armenia, Kazakhstan and the Russian Federation, family doctors are not allowed to diagnose or treat people with mental health problems. They are not authorised to prescribe psychotherapeutic medication, be it at their own initiative or on the basis of recommendations from specialists. Doctors in Moldova and Uzbekistan are authorised to do so, but only under certain conditions. In contrast, family doctors in Azerbaijan, Belarus and Georgia are permitted to both diagnose and treat people with mental health problems. Unlike doctors, nurses are not allowed to undertake any role in mental health carSecond, regardless of whether they are authorised or not to provide mental health care, the competencies of primary care staff in mental health are limited. In certain countries (e.g., Uzbekistan, Kyrgyzstan, Azerbaijan), family doctors received some training in mental health with expert and financial support from WHO. In others (e.g., Republic of Moldova, ${ }^{42}$ Ukraine), some basic courses are included in the standard training of resident family doctors. In the Russian Federation there are reports of training courses that are carried out at the regional level. ${ }^{43}$ At the same time, there are hardly any courses in mental health for nurses working in primary care. As such, psychiatrists are often reluctant to delegate primary care staff responsibilities in diagnosing and treating people with mental health problems. The links with specialised services are poor, and in most countries referral mechanisms are not in place. Psychiatrists tend to advice their patients to return to their specialised services for regular check-ups, sometimes justifying it with the need for ensuring the continuity of care. At psychiatrists' counter-advice, few patients are likely to choose their family doctor as their care coordinator.

Third, even where mental health specialists would like to engage with family doctors, another challenge is that family doctors are already overburdened, and are reluctant to take on more responsibilities. In the first years after the reforms of the primary care sector, family doctors were asked to take on responsibilities for other health conditions which were prioritised at the time, due to their high burden of disease and mortality rates. As such, in many CIS countries they manage the directly observed treatment of TB, maternal care, etc. As these health topics benefit from high international awareness, introduction of these services in primary care was often sponsored by international donors, and family doctors were incentivised to take them up and to perform well. Despite political statements, mental health remains a low priority internationally, and only a few donors have 
invested in reforms of mental health services in CIS countries. As such, considering their already high workload and the lack of incentives, family doctors are reluctant to assume new responsibilities in mental health care.

Furthermore, while intended to mitigate the stigmatising impact of institutional care, transfer of responsibilities for mental health care to primary care in CIS raises different concerns with regards to protection of human rights of patients. Mental health specialists and people with mental health problems have low confidence in the ability of primary care staff to maintain the confidentiality of patient data. These concerns regard particularly the nursing staff that has little or no training in mental health. While the mental health legislation recently adopted in most of the CIS countries protects patients' right to confidentiality, there are hardly any mechanisms to monitor the implementation of the law, or deal with complaints regarding violations. As such, even when family doctors offer mental health care locally, patients choose to access specialised services in large towns. The poor information system ensures that patients' data does not reach local health professionals, and patients can keep their mental health problems hidden from the communities where they live.

\section{REFLECTIONS AND CONCLUSIONS ON CHALLENGES TO REFORMING MENTAL HEALTH CARE IN CIS COUNTRIES}

Twenty years after the breakdown of the Soviet Union, all but one of its former republics (Turkmenistan) have adopted new mental health legislation. ${ }^{20}$ Some countries have also adopted mental health policies or plans of action (Azerbaijan, Belarus, Republic of Moldova, Russian Federation, Ukraine and Uzbekistan). The adoption of these legal and policy documents represented a first step in the direction of modernising mental health.

However, in themselves, they had little impact. This is due, on one side, to the fact that their adoption did not emerge from acknowledged needs at the national level, or genuine willingness to change. Instead, their development was instigated by international organisations, with mandates covering health care and/or human rights, such as WHO or the Council of Europe. These new national documents largely duplicate different international mental health policies and international human rights legislation (e.g., WHO European Mental Health Action Plan, ${ }^{44}$ or the United Nations conventions on human rights $\left.{ }^{4-47}\right)$. As such, they do meet the international requirements. However, because they draw on such comprehensive documents targeted at a large number of countries in various stages of development, they are not exact enough to reflect the local needs and resources. They are often unfocused, 
setting high expectations on too many priority areas. They also lack pragmatic targets, concrete deadlines for meeting them, and they have no funding attached or mechanisms for monitoring their implementation. These shortcomings of mental health policies in CIS countries are indicative of the low level of commitment of decision makers and key stakeholders to deliver on the priorities set. As such, while international pressure to initiate change through policy and legislation was justified and positive in its own right, it largely failed to generate substantial reforms of the mental health systems. Instead they allowed countries to report internationally that they meet the international requirements, formally satisfying vocal requests for action from national champions, irrespective of the scale of implementation.

On the other hand, even when decision makers in health are behind the process of change, they often lack the resources to drive it. To generate change, the support from the international community would need to go beyond the development of policy papers. The development and adoption of national legislation and policy was not within the financial means of most CIS governments. Although some countries benefited from international support for the work of national experts and key stakeholders, the funds required were modest. ${ }^{48-53}$ The implementation of commitments, however, would require significant investments. According to the World Bank classification, the CIS countries include two of the poorest countries in the world (Kyrgyzstan and Tajikistan) and five lower-middle-income economies (Armenia, Georgia, Moldova, Ukraine, Uzbekistan). Countries with low levels of resources rely on international donations for implementing large-scale reforms, in health or otherwise. As such, it can be said that the pace of implementing the reforms in mental health reflects the level of interest and support offered by the international community to the governments of these countries. While donations and pressure focused on other health conditions, such as maternal care, mortality among children under five years of age, TB, cardiovascular disorders, or HIV, little progress has been achieved in mental health.

A further challenge, with implications that go beyond the scope of mental health care, is that after years of government imposed values, social cohesion largely vanished in many of the former Soviet countries. The concept of community, a cornerstone in modern mental health services, is at best shaky, if not lost in these countries that went through decades of dictatorship, plagued by generalised distrust among people that spilled over into every aspect of the social life. In addition, many people lost a sense of belonging and of community due to deportations and massive population moves that reshaped the structures of small and large communities. The 
trajectory of care in the post-Soviet societies is very different from that in Western countries where modern community mental health care first developed and flourished over the last decades. Reforms of mental health services in CIS countries will need to take account of these differences and translate culturally basic concepts, such as community-based mental health care, with recognition of the socialising and networking patterns in these countries.

To conclude, there are no easy solutions to reforming the mental health systems anywhere and in particular in the former Soviet countries. Instigating genuine and lasting changes will require complex interventions, combining anthropological approaches with greater resources allocated within these countries along with international financial support as these countries on their own cannot afford to implement indispensable reforms. Recognition by health and political authorities of the scope and severity of mental health issues is perhaps the first and most important phase with information systems in place to monitor care. Policy development and resource allocations are then vital next steps. Credible commitment from national decision makers is essential to the mental health agenda and to driving the process of change and delivery of good mental health care. It is not an impossible target, but with reforms in the early stage of implementation, and slim prospects of suitable resources for necessary investments, modern mental health services remain for now largely out of reach for most people in former Soviet countries.

Acknowledgments: I would like to thank Prof. Ted Tulchinsky for his advice, editing and continuous support. My thanks also go to Ms. Marina Lazeri for her assistance in systematizing the data used in the article.

Conflicts of Interest: None declared.

About the Author: Dr. Ionela Petrea heads the international department for mental health and tobacco control of the Trimbos Institute, the Dutch Institute for Mental Health and Addictions. As part of her responsibilities, she shapes the international agenda and coordinates the international activities on mental health, focused on mental health systems reforms, clinical guidelines, e-mental health, mental health economics, treatment, recovery and reintegration of people with severe mental illness; and mental health of young people and older people. Before joining Trimbos, Dr. Petrea worked for 9 years for WHO EURO where she was involved in mental health policy development, coordinated mental health systems assessments and worked on service reform agenda with countries from the Central and Eastern part of the Region.

Dr. Petrea received her basic training in psychology and psychotherapy in Romania. She has a MSc in International Health from the University of Copenhagen and a $\mathrm{PhD}$ in Medicine from the LSHTM. 


\section{REFERENCES}

1. World Psychiatric Association. Member Societies. 2013. Available from URL: http://www.wpanet.org/detail.php?section_id=5\&content_id=674\&sort_ by $=\mathrm{T}$ (accessed 16 September 2013).

2. Gordon H, Meux C. Forensic psychiatry in Russia: past, present and future. Psychiatrist. 2000;24:121-3.

3. Bonnie RJ. Political abuse of psychiatry in the Soviet Union and in China: complexities and controversies. J Am Acad Psychiatry Law. 2002;30:136-44.

4. Birley J. Political abuse of psychiatry in the Soviet Union and China: a rough guide for bystanders. J Am Acad Psychiatry Law. 2002;30:145-7.

5. United States Delegation to Assess Recent Changes in Soviet Psychiatry. Report of the U.S. Delegation to Assess Recent Changes in Soviet psychiatry. Schizophr Bull. 1989;15(4 Suppl):1-219.

6. van Voren R. Political abuse of psychiatry--an historical overview. Schizophr Bull. 2010 Jan;36:33-5.

7. World Psychiatric Association General Assembly. The Declaration of Hawaii. Honolulu (HI): World Psychiatric Association; 1977. Amended, Vienna, Italy; 1983.

8. Ougrin D, Gluzman S, Dratcu L. Psychiatry in post-communist Ukraine: dismantling the past, paving the way for the future. Psychiatrist. 2006;30:456-9.

9. Jenkins R, Lancashire S, McDaid D, Samyshkin Y, Green S, et al. Mental health reform in the Russian Federation: an integrated approach to achieve social inclusion and recovery. Bull World Health Organ. 2007;85:858-66.

10. Phillips SD. Disability and Mobile Citizenship in Postsocialist Ukraine. Bloomington, (IN): Indiana University Press; 2011.

11. Fefelov V. V SSSR invalidov net! (There are no Invalids in the USSR!) London: Overseas Publications Interchange Ltd.; 1986.

12. Phillips SD. "There are no invalids in the USSR!": a missing Soviet chapter in the new disability history. Disabil Stud Q. 2009;29(3).

13. Mundt AP, Franciskovic T, Gurovich I, Heinz A, Ignatyev Y, et al. Changes in the provision of institutionalized mental health care in post-communist countries. PLoS One. 2012;7:e38490.

14. Jenkins R, Klein J, Parker C. Mental health in post-communist countries. BMJ. 2005;331:173-4.

15. Bromet EJ, Gluzman SF, Paniotto VI, Webb CP, Tintle NL, et al. Epidemiology of psychiatric and alcohol disorders in Ukraine: findings from the Ukraine World Mental Health survey. Soc Psychiatry Psychiatr Epidemiol. 2005;40: 681-90.

16. World Health Organization. The global burden of disease: 2004 update. Geneva: WHO; 2008.

17. Petrea I, Muijen M. Policies and practices for mental health in Europe. Copenhagen: WHO Regional Office for Europe; 2008. 
18. WHO Regional Office for Europe. European mortality database. January 2010 edition. WHO Regional Office for Europe; 2012. Available from URL: http:// data.euro.who.int/hfamdb/ (accessed 20 November 2012).

19. World Health Organization. European Regional Information System on Resources for the Prevention and Treatment of Substance Use Disorders. Geneva: WHO; 2013. Available from URL: http://apps.who.int/gho/data/ node.main-euro.RSUD?lang=en?showonly=RSUD (accessed 25 August 2013).

20. World Health Organization, Department of Mental Health and Substance Abuse. Mental Health Atlas 2011. Geneva: WHO; 2011.

21. World Health Organization, Department of Mental Health and Substance Abuse. Mental Health Atlas 2011. Armenia. Geneva: WHO; 2011. Available from URL: http://www.who.int/mental_health/evidence/atlas/profiles/arm mh_profile.pdf (accessed 20 November 2012).

22. World Health Organization, Department of Mental Health and Substance Abuse. Mental Health Atlas 2011. Azerbaijan. Geneva: WHO; 2011. Available from URL: http://www.who.int/mental_health/evidence/atlas/ profiles/aze_mh_profile.pdf (accessed 20 November 2012).

23. World Health Organization, Department of Mental Health and Substance Abuse. Mental Health Atlas 2011. Belarus. Geneva: WHO; 2011. Available from URL: http://www.who.int/mental_health/evidence/atlas/profiles/blr_ mh_profile.pdf (accessed 20 November 2012).

24. World Health Organization, Department of Mental Health and Substance Abuse. Mental Health Atlas 2011. Georgia. Geneva: WHO; 2011. Available from URL: http://www.who.int/mental_health/evidence/atlas/profiles/geo_ mh_profile.pdf (accessed 20 November 2012).

25. World Health Organization, Department of Mental Health and Substance Abuse. Mental Health Atlas 2011. Kazakhstan. Geneva: WHO; 2011. Available from URL: http://www.who.int/mental_health/evidence/atlas/ profiles/kaz_mh_profile.pdf (accessed 20 November 2012).

26. World Health Organization, Department of Mental Health and Substance Abuse. Mental Health Atlas 2011. Republic of Moldova. Geneva: WHO; 2011. Available from URL: http://www.who.int/mental_health/evidence/ atlas/profiles/mda_mh_profile.pdf (accessed 20 November 2012).

27. World Health Organization, Department of Mental Health and Substance Abuse. Mental Health Atlas 2011. Russian Federation. Geneva: WHO; 2011. Available from URL: http://www.who.int/mental_health/evidence/atlas/ profiles/rus_mh_profile.pdf (accessed 20 November 2012).

28. World Health Organization, Department of Mental Health and Substance Abuse. Mental Health Atlas 2011. Tajikistan. Geneva: WHO; 2011. Available from URL: http://www.who.int/mental_health/evidence/atlas/profiles/taj_ mh_profile.pdf (accessed 20 November 2012). 
29. World Health Organization, Department of Mental Health and Substance Abuse. Mental Health Atlas 2011. Uzbekistan. Geneva: WHO; 2011. Available from URL: http://www.who.int/mental_health/evidence/atlas/ profiles/uzb_mh_profile.pdf (accessed 20 November 2012).

30. McCulloch A, Muijen M. Mental health. In: Walshe K, Smith J, (editors). Healthcare Management. Maidenhead: McGraw-Hill; 2011.

31. Krasnov V, Gurovich I. History and current condition of Russian psychiatry. Int Rev Psychiatry. 2012;24:328-33.

32. Cheian-Andrei D. Feasibility study regarding the development of the mental health services in the Republic of Moldova. Chisinau: Swiss Agency for Development and Cooperation; 2011.

33. WHO Regional Office for Europe. Merano Declaration on mental health in CIS countries. Merano: WHO Regional Office for Europe; 2008.

34. Mental Health Foundation of Armenia. Community based service program. Available from URL: http://www.mentalhealth.am/ (accessed 20 November 2012).

35. Swiss Agency for Development and Cooperation. Mental Health Project. Chisinau: Swiss Agency for Development and Cooperation; 2012. Available from URL: http://www.swiss-cooperation.admin.ch/moldova//ressources/ resource_en_206404.pdf (accessed 20 November 2012).

36. Association SOMATO. Raport de evaluare privind activitatea centrelor comunitare de sanatate mintala din Republica Moldova. Chisinau: Ministry of Health of Moldova; 2012. [In Romanian]

37. Global Initiative on Psychiatry. Developing and piloting sheltered housing service for people with mental illness. 2011. Available from URL: http://www. gip-global.org/p/44/411/\%93sheltered-housing\%94-service-was-launchedin-balti-moldova (accessed 20 November 2012).

38. Priebe S, Matanov A, Demi N, Blagovcanin Simic J, Jovanovic S, et al. Community mental health centres initiated by the South-Eastern Europe Stability Pact: evaluation in seven countries. Community Ment Health J. 2012;48:352-62.

39. Balabanova D, McKee M, Pomerleau J, Rose R, Haerpfer C. Health service utilization in the former Soviet Union: evidence from eight countries. Health Serv Res. 2004;39:1927-50.

40. Borowitz M, O’Dougherty S, Wickham C, Hafner G, Simidjiyski J, et al. Conceptual Foundations for Central Asian Republics Health Reform Model. Almaty: USAID/CAR; 1999.

41. WHO Regional Office for Europe. European Health for All Database. January 2013. Available from URL: http://www.euro.who.int/en/what-we-do/dataand-evidence/databases/european-health-for-all-database-hfa-db2 (accessed 11 April 2013). 
42. Galbur O. Raport cu privire la analiza comparativa a clasificatorului si nomenclatorului specialitatilor medicale din UE si Republica Moldova cu propuneri concrete de modificari si ajustari la standardele europene. Chisinau: Ministry of Health of Moldova; 2010. [In Romanian]

43. Zakroyeva A, Goldberg D, Gask L, Leese M. Training Russian family physicians in mental health skills. Eur J Gen Pract. 2008;14:19-22.

44. WHO Regional Office for Europe. Mental Health Action Plan for Europe. Facing the challenges, building solutions. Copenhagen: WHO Regional Office for Europe; 2005.

45. United Nations General Assembly. Universal Declaration of Human Rights. Resolution 217 A (III). New York (NY): United Nations; 1948.

46. United Nations General Assembly. Principles for the protection of persons with mental illness and the improvement of mental health care. Resolution 46/119. New York (NY): United Nations; 1991.

47. United Nations General Assembly. Convention on the Rights of Persons with Disabilities. New York (NY): United Nations; 2006.

48. WHO Regional Office for Europe. Biennial Collaborative Agreement (BCA) between the Ministry of Health of Azerbaijan and the Regional Office for Europe of the World Health Organization 2008/2009. Copenhagen: WHO Regional Office for Europe; 2007.

49. WHO Regional Office for Europe. Biennial Collaborative Agreement (BCA) between the Ministry of Health of Kyrgyzstan and the Regional Office for Europe of the World Health Organization 2008/2009. Copenhagen: WHO Regional Office for Europe; 2007.

50. WHO Regional Office for Europe. Biennial Collaborative Agreement (BCA) between the Ministry of Health of Tajikisan and the Regional Office for Europe of the World Health Organization 2010/2011. Copenhagen: WHO Regional Office for Europe; 2009.

51. WHO Regional Office for Europe. Biennial Collaborative Agreement (BCA) between the Ministry of Health of Tajikistan and the Regional Office for Europe of the World Health Organization 2008/2009. Copenhagen: WHO Regional Office for Europe; 2007.

52. WHO Regional Office for Europe. Biennial Collaborative Agreement (BCA) between the Ministry of Health of the Republic of Moldova and the Regional Office for Europe of the World Health Organization 2010/2011. Copenhagen: WHO Regional Office for Europe; 2009.

53. WHO Regional Office for Europe. Biennial Collaborative Agreement (BCA) between the Ministry of Health of Uzbekistan and the Regional Office for Europe of the World Health Organization 2008/2009. Copenhagen: WHO Regional Office for Europe; 2007. 